\title{
Eros y Tanatos: representación de la melancolía en Ophelia
}

\author{
Erika Rodríguez Vásquez \\ erika.rodriguezv77@gmail.com
}

\section{Resumen}

El objetivo principal de este artículo es discutir la representación de la melancolía como resultado de la tensión entre lo erótico y lo mórbido en el poemario Ophelia. Este predominante sentimiento melancólico en los versos, que constituyen el libro se analizará a partir de la correspondencia entre dos ejes: el eros y el tanatos, como fundamentos en la percepción de un tono catastrófico y el carácter mítico del personaje ofeliano. En ese sentido, se pondrá énfasis en evidenciar la presencia de un discurso y tono en el marco de creación de fin de siglo.

Palabras Clave: Ofelia, escritura poética, eros y tanatos; tono melancólico; fin de siglo.

\begin{abstract}
The main purpose of this article is to discuss the representation of melancholy, as a result of the tension between the erotic and the morbid in the poetry book Ophelia. This predominantly melancholic feeling in the book verses will be analyzed taking into account the correspondence between two axes: eros and tanatos, as foundations in the perception of a catastrophic tone and the mythical character of the Ofelian character. In this sense, emphasis will be placed on demonstrating the presence of a discourse and tone within the framework of the creation and spirit of the end of the century.
\end{abstract}

Keywords: Ofelia; poetic writing; eros and tanatos; melancholic tone; end of the century. 


\section{Eroos y Tanatos: representación de la melancolía en Ophelia}

\section{Introducción}

En el año 2001, la artista visual alemana Gundula Schulze Eldowy ${ }^{1}$ presentó una exposición de fotografías correspondientes a los años 1975 a 1990 donde retrató las huellas decadentes dejadas por la guerra en la ciudad y en los habitantes de Berlín Oriental. La fotógrafa reflexionó sobre el significado de estas imágenes y escribió sobre el futuro, de cómo la humanidad se iría destruyendo hasta solo escuchar el sonido quejumbroso de su voz. Esta preocupación por retratar el estado anímico vinculado al malestar por la realidad cruel circundante es un tema recurrente y motivo para los creadores. Es así que el tópico de la melancolía ha estado presente desde la antigüedad clásica y ha adquirido, según la cultura y la época, cierta importancia y valoración como por ejemplo, en el siglo XIX, durante el periodo del Romanticismo. Actualmente, su vigencia se encuentra asociada, incluso, como un estado ideal de contemplación artística, tal como lo advierte la teórica y filóloga española Remedios Perni Llorente en su estudio sobre Ofelia: melancolía y la cultura visual: "El ánimo melancólico del artista" —o del pensador- prevalece en nuestros días, pese a sus momentos de desprestigio, como caracterización de cierto talento creativo". (Perni, 2014, p. 131) En el presente artículo se analizará dicho concepto y su representación en los poemas del libro Ophelia. (Rodríguez, 2013)

\section{Metodología}

La indagación pretende abordar el concepto de la melancolía y su representación desde el análisis de dos ejes que configuran el poemario: eros y tanatos, para así establecer su relación en la percepción de un tono catastrófico y desolador. Se apela a un estudio por lo estético y simbólico que pueda reconocer; además, la apropiación de elementos intertextuales y relecturas del carácter mítico del 
personaje shakesperiano. Para analizar los poemas se revisará el lenguaje poético, el sentido de los versos y su relación con la intertextualidad mencionada.

Del mismo modo, se tomará en cuenta los conceptos de melancolía desarrollados por pensadores a través del tiempo y la confrontación del concepto de erotismo propuesto por Freud (1973) y el de la poeta norteamericana Audrey Lorde (1978), con respecto a la afirmación del uso del erotismo como poder de las figuras femeninas para ocupar un espacio en el lenguaje, en la historia, etc.

\section{Erosy Tanatos}

En este poemario, compuesto por 10 textos, encontramos dos ejes importantes para comprender la enunciación del tono melancólico. En primer lugar, existe una fuerte carga erótica debido al uso del elemento del cuerpo (femenino/ masculino/ andrógino). Se trata, además, de un erotismo por lo mórbido ya que la voz poética relata siempre el estado de un cuerpo en una atmósfera de muerte. En ese sentido, los versos refieren siempre un doble hundimiento, el del cuerpo y el de la realidad que los rodea. En el pensamiento freudiano, tanto eros como tanatos están definidos como dos instintitos básicos que acompañan a la humanidad y a la sociedad a lo largo de la vida. Por lo tanto, eros representa a los instintos vitales y elevados, mientras que tanatos refiere a los instintos de muerte y destrucción. Esta definición nace del filósofo griego Empédocles de Agrigento (siglo a. C.) y es tomada por el psicoanalista para explicar la complejidad de la naturaleza humana y su teoría sobre las pulsiones en el estudio "El malestar de la cultura". Contemporáneamente, lo erótico también suele relacionarse con una afirmación de poder. La poeta estadounidense, Audre Lorde, define eros, como la personificación del amor en todos sus aspectos; nacido de Caos, Eros personifica el poder creativo y la armonía. En su ensayo: "Usos de lo erótico, lo erótico como poder" (1978), posiciona su uso como un poder para validar la fuerza inagotable y provocadora en la mujer. Para Lorde, históricamente se ha negativizado el término cuando ha sido detentado por la mujer o se ha usado en su contra para poder controlarla o servirse de ella. Además se ha sancionado a la que rompe ese control y usa lo erótico a su derecho y placer. Por tanto, Lorde propone la apropiación de lo erótico como una afirmación de ese poder y reclamar un espacio en el lenguaje, en la historia, en el trabajo y en todos los aspectos de la vida. Interesa, en este punto, interpretar la pulsión de eros en el poemario analizado como un camino hacia un nuevo conocimiento, al entendimiento de otros contornos de realidad y como lo explica Audre Lorde, el de proporcionar visibilidad, poder y espacio a esas nuevas relecturas que se enuncian sobre el personaje.

En segundo lugar, el eje del tanatos es desarrollado desde el lenguaje, pues es a partir de este donde se construye la atmosfera que permite la creación de 
un discurso ofeliano y que fusione, además, a la dama con la noche, con el agua, con lo oscuro, entre otras metáforas. En esas circunstancias, la representación de la melancolía se hace evidente cuando se hace uso de un tono catastrófico y desolador (característica que ha acompañado al personaje a lo largo del tiempo). Los signos que reforzarían la existencia de ese tono, se encuentran en el uso de un leguaje fáctico donde se construye lo lúgubre y lo sombrío, como lo expresan los siguientes versos: "Campanas de la muerte / llaves negras / estoy muerta / la mano envejecidal el cadáver de la mañana / un sonido muerto". Por lo tanto, se puede afirmar que acechar el tópico de la melancolía en el poemario se traduce en acechar dicho tono catastrófico y desolador.

La acepción de tanatos deriva de la definición que dio Freud al mito griego, por tanto nos ceñiremos a ella, entendiendo el término como la pulsión de la muerte en los instintos de autodestrucción. En los versos que estructuran el poemario Ophelia, dicho instinto se encuentra fortalecido en las descripciones de mujeres suicidas, ausentes, conflictuadas, depresivas o al borde de la locura. Así, el yo poético enuncia una voz en constante lucha hacia la desintegración. Según algunos expertos en psicología, lo tanático puede referirse, también, a otras manifestaciones sociales de destrucción y desunión como las guerras, un genocidio, persecuciones, etc.

\section{Ofelia y el mito}

Con respecto al personaje evocado en el poemario, resulta oportuno tomar en cuenta las ideas que algunas teóricas sostienen sobre la importancia de estudiar la entramada relación de correspondencia entre la cosmovisión y la producción artística a lo largo del tiempo y en diferentes épocas para poder ver la evolución del pensamiento en la percepción de algunos modelos o íconos de la cultura actual. En el caso del personaje trágico de Ofelia, en Hamlet, del autor inglés William Shakespeare, siempre se la ha caracterizado desde la patología como una mujer-niña, virginal e inocente desbordada por la pasión amorosa o por la enfermedad mental. Al respecto, Remedios Perni, citando a Rebeca Comay, advierte que en la historia del término melancolía ha existido una fase denigratoria que ha tenido por lo general a la mujer como protagonista. En el poemario que analizamos se verifica el registro de estos principios tradicionales del mito de Ofelia (su existencia sigue siendo catastrófica y trágica), pero se alteran y reajustan para añadir otras interpretaciones y construir una relectura del personaje. De ese modo, Ofelia se convierte en metáfora y discurso presente en el texto, la melancolía aludida es entendida como parte de la naturaleza humana (tensión entre la vida y la muerte) y la realidad que se confronta, constituyen los límites relacionados a la falta de poder, al vacío e incertidumbre que acerca a la destrucción. 
Como se observa, la experiencia creativa resalta el carácter inagotable del personaje y no sorprende que el mito de Ofelia se actualice y esté presente en la expresión artística contemporánea. Por otra parte, ayuda a transparentar la importancia y atención al concepto de lo que consideramos "la tradición", su posterior crisis y la asimilación de una mirada crítica que permita desmontar y reflexionar sobre una apropiación del discurso, a partir de nuevas estructuras, materiales, procedimientos, temas etc. Así, es claro ahora, que a través de la intertextualidad, que pone en manifiesto la heterogeneidad, el poemario puede girar hacia otros significados, signar otras experiencias y experimentar en diversos planos con otros soportes de creación. Veamos cómo se despliega lo erótico en el poema "HAWTHORNE'S EXPERIMENT":

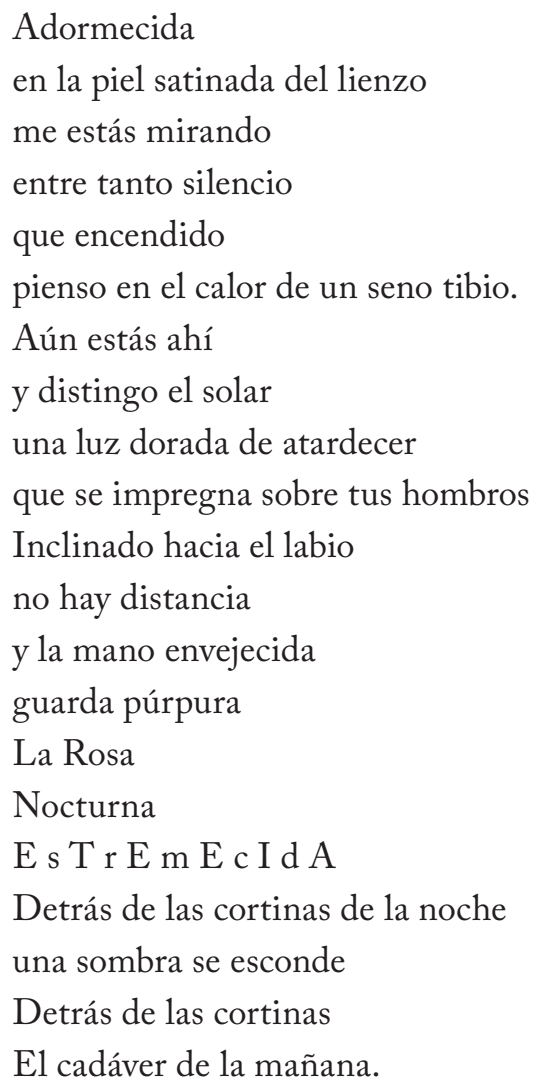

(Rodríguez, 2013, p. 19)

Es clara la influencia de la intertextualidad en este poema en el que se hace alusión a un cuento de carácter fantástico del escritor norteamericano Nathaniel Hawthornes. La brevedad en los versos confecciona un efecto enigmático y lúdico en las imágenes donde se empieza a erotizar el cuerpo de la amada que se recuerda. El tono personal de la voz poética que lamenta la distancia 
y la imposibilidad del lance amatorio evidencia la presencia inminente de la destrucción y la fugacidad de la juventud. En dichas descripciones de insatisfacción, la voz poética deja de ser febril y se torna serena. El ambiente exotista, donde ocurre el recuerdo erótico, es signado prontamente por la oscuridad de la noche, en la cual se instaura un profundo ambiente de sombra. Ofelia puede ser esa rosa nocturna y adormecida, inmortalizada en el lienzo del recuerdo o acaso el cadáver que se descubre con malicia a la luz de la mañana.

\section{Ofelia y su pasión por la tristeza}

Remedios Perni recoge algunas definiciones a partir del minucioso estudio que Robert Burton (1621), contemporáneo de Shakespeare, hace sobre el carácter de la melancolía. Una de ellas es la de Hipócrates, quien consideraba a la melancolía como una enfermedad. Mientras que para Burton, los melancólicos eran seres, cita Perni: "arrastrados inexorablemente por la pasión de la tristeza”. ${ }^{2}$ Sin embargo — advierte la teórica- gran parte de la leyenda que se ha tejido sobre Ofelia en las últimas décadas en la cultura occidental tienen su origen en el modelo que recreó el artista prerrafaelista John Everest Millais, (1851-52) quien retrató con profundo dramatismo melancólico a su joven musa Elizabeth Siddal. Por lo tanto, no sorprende que observemos dicha influencia en los referentes del libro, pues sirven para explicar las metáforas empleadas: la mujer es la noche, es el agua, la muerte, el ahogo, etc. De acuerdo a esto podemos afirmar que existe en los versos del poemario una fuerza vital que se desprende de lo erótico y palidece con el ensombrecimiento y melancolía que da paso al contraste de la muerte. Así, configurada la tensión mencionada, entre lo erótico y lo tanático, el contraste se hace palpable con el cambio de registro que algunos de los poemas presentan, sin interrumpir el ritmo desplegado en el texto.

\section{La catástrofe y la desolación}

La apropiación del mito del personaje de Ofelia, tradicionalmente se ha construido desde una simbolización en la que se enuncia a la mujer desbordada por la insania mental o la desesperación suicida. Esta encarnación guarda relación, dentro de una atmósfera de contemplación, con el estado melancólico que se presenta en el poemario, en tanto que el yo poético transita de la luz a la sombra por la soledad, ausencia, locura, maternidad etc. Así el contorno de realidad evidencia un mundo en crisis, que además, le es adverso y la lleva a su quiebre final, su entrega de la vida hacia la muerte. Ciertamente, dicha atmósfera, se mantiene a partir del mito del personaje desafortunado de Ofelia en la obra de Shakespeare, pero el discurso es construido desde una nueva mirada que transciende el tiempo y puede permitir, incluso, abordar la condición de la mujer 
actual. Así, encontramos textos como "INSOMBRA", "OLEO DE KLIMT" donde se tocan temas como la maternidad interrumpida, aunque de manera sesgada, no dejan de sugerir el mismo hálito de destrucción. Por lo tanto, podemos sostener, que Ofelia será entonces el personaje metafóricamente encarnado y se convertirá en presencia y discurso en todo el poemario a partir de dicha atmósfera melancólica, la cual dotará de un cariz de enfermedad, oscuridad y muerte a los poemas.

\section{Melancolía y Fin de Siglo}

A partir de la percepción de un tono catastrófico y desolador puede rastrearse el retorno a algunos conceptos decadentistas y reflexionar sobre la existencia de un tono fin de siècle en el poemario, pues el uso de un lenguaje fáctico y lúgubre, que da presencia a metáforas vivas, sobre todo a mujeres al borde de una crisis, marca una estrecha relación con el espíritu de pesadumbre y angustia que responden a una manera de sentir el fin de siglo. Por otro lado, el diálogo con otros discursos extraliterarios como la pintura y la música según se observa en los títulos de los poemas como: "OLEO DE KLIMT / MARGARETH ON THE GUILLOTINE / ATMOSPHERE/ KOMAKINO” además de precisar heterogeneidad y experimentación, refuerzan, aún más, el registro de referentes relacionados con el tono del "spleen" del fin de siècle.

El fin de siècle no solo está entendido como el fin de una centuria, el término acuñado en francés, tiene una connotación de periodo específico del siglo XIX, que incluso podría abarcar los primeros años del siglo venidero, donde se hace alusión a una gama de movimientos artísticos como el simbolismo o decadentismo, asociados por lo general a la cultura francesa y a occidente. Se entiende, también, que su atmósfera creativa estará en tensión constante con una desesperada expectativa por el cambio, lo cual revelará que toda su producción dejará traslucir la crisis del modelo societal dentro de la sociedad moderna.

El escritor francés, Huysmans, afirmó, hace mucho tiempo, que todos los fines de siglo se parecen. En El viaje Entretenido (2016), Luis Iglesias Feijoo, analiza el contexto socio cultural del fin de siglo anterior, como punto de referencia para reflexionar sobre nuestro propio fin de siglo y explicar las circunstancias en las que se produjeron las manifestaciones literarias y artísticas contra un sistema estético anterior. En este punto conviene advertir que tal reflexión lo llevó a afirmar que "estos balances de fin de siglo, suelen estar dominados por un tono catastrófico" . A nuestro juicio, no deja de ser interesante que se indague y señale la conciencia de una crisis, como punto de partida, para abordar el contexto de creación del fin de siglo, ya que ello revelaría un ambiente dominado por una reacción desbordada por el cambio a un modelo nuevo. En todo caso, lo que importa para nuestro análisis es advertir que en el ocaso de 
todo siglo, dicha crisis se encuentra relacionada con la idea de una conciencia sobre un futuro próximo que se desconoce, y que para enunciarse con identidad propia deberá romper con el paradigma anterior para proponer lo nuevo.

\section{Conclusiones}

En Ophelia, ciertamente existe la tensión entre ambos instintos como dos ejes polares por los que transitan el yo poético. Así, el punto de partida desde donde se enuncia siempre será desde el eros y paulatinamente será vencida por el tanatos. El tono melancólico y lúgubre que encontramos en movimientos como el decadentismo, son expresiones de la crisis de todo fin de siglo, pero en la actualidad (2000) ya no se puede reconocer solo una sino varias tradiciones que se rompen, se versionan, o se reactualizan, en diferentes expresiones artísticas. Es por ello que proponemos que en el poemario Ophelia, publicado en el año 2013, se insinúa un tono "fin de siècle", ya que existe una apropiación del discurso ofeliano desde la representación de la melancolía, la simbolización y la tensión entre eros y tanatos.

En el ámbito de las artes plásticas, el término "fin de siècle" adquiere algunos análisis más profundos. Lise Martinot, reflexiona y señala que el término, el cual reúne varias manifestaciones artísticas, agrupa también, una serie de principios y actitudes que pueden llevar a afirmar que funcionó como antítesis del modernismo. Así, para Martinot, el decadentismo es entendido como un movimiento esteticista, despolitizado y feminizador del arte. Donde podemos explorar los estereotipos de lo femenino y su relación con señalar en ella la idea de lo irracional.

Desde los estudios de las artes plásticas, se puede afirmar que lo femenino, a principios de siglo XX, era asociado a lo negativo, a la enfermedad, mientras que lo moderno, afianzado, desde sus inicios, en los modelos de la razón, solo permitía el horizonte de un nuevo orden de poder sustentado por lo patriarcal. Así, lo ordenado y estructurado eran valores que configuraban lo masculino.

En la actualidad, el paradigma de lo femenino está cambiando desde un enfoque del género. La diversidad del género otorga por tanto, también, una tensión entre el modelo tradicional y la ruptura. No sorprende tampoco que el mito de Ofelia se actualice y esté presente en la expresión artística contemporánea.

Se puede dar la reflexión, por tanto, que el tono catastrófico y desolador del "fin de siècle" está presente en el poemario Ophelia, y se encuentra desde la evocación del personaje trágico de la mujer suicida y en la representación de la melancolía traslucida en la pulsión entre eros y tanatos. 
El poemario propone la creación de un discurso ofeliano proveniente de la obra de Shakespeare y del carácter mítico del personaje, que a lo largo del tiempo otros autores, artistas y otros soportes artísticos han evidenciado la evolución del personaje. El mecanismo en el proceso creativo del poemario es la apropiación lúdica y experimental, a partir del cual, se construye una relectura del personaje tradicional de Ofelia.

\section{Notas}

1 Se hace referencia a la exposición individual "Berlin. En una noche de perros" en la Galería Germán Kruguer de Miraflores, Lima-Perú. 2001.

2 Robert Burton, Anatomy of Melancholy, p.185. Citado por Remedios Perni, Recordando a Ofelia: Melancolia y Cultura visual, p. 143.

3 Iglesias Feijoo, El viaje entretenido: Estudios de literatura española, p 21.

\section{Referencias}

Capona Perez, D. (2004). Ofelia o el Mal Imaginario. Estudio de la evolución del personaje de Ofelia en tres obras dramáticas desde una mirada de género. (Tesis para optar el grado de Magister en Artes con mención en Dirección Teatral). Universidad de Chile. Facultad de Artes, Santiago de Chile. http://repositorio. uchile.cl/tesis/uchile/2004/capona_d/sources/capona_d.pdf

Gutierrez Girardot, R. (2004). Modernismo: supuestos históricos y culturales. México D.F.: Fondo de Cultura Económica.

Henriquez Ureña, M. (1962). Breve historia del Modernismo. México: Fondo de Cultura Económica.

Iglesias Feijoo, L. (2016). El viaje entretenido: Estudios de literatura española. Galicia: Universidad de Santiago de Compostela.

Lyotard, J. F. (2006). La Condición posmoderna. Madrid: Cátedra.

Martinot, L. (2009). Fin de Siécle en Europa, o Una Crisis del Sitema Modernista. (Tesis de Magister en Artes con mención en Teoría e Historia del Arte), Universidad de Chile. Facultad de Artes, Santiago de Chile. www.cybertesis.uchile.cl/tesis/ uchile/2009/ar-martinot_1/pdfAmont/ar-martinot_l.pdf.

Paz, O. (1990). La otra voz, poesía y fin de siglo. Barcelona: Seix Barral.

Perni Llorente, R. (2014). Recordando a Ofelia: Melancolia y Cultura visual. (Tesis de Doctor por la Universidad de Murcia), Universidad de Murcia. Departamento de Filología Inglesa, Murcia. http://www.tdx.cat/handle/10803/284813

Rodríguez, E. (2013). Ophelia. Lima: Escalante Editores. 